Review Article

\title{
Maturation, Refinement, and Serotonergic Modulation of Cerebellar Cortical Circuits in Normal Development and in Murine Models of Autism
}

\author{
Eriola Hoxha, ${ }^{1,2}$ Pellegrino Lippiello, ${ }^{3}$ Bibiana Scelfo, ${ }^{2}$ Filippo Tempia, ${ }^{1,2,4}$ \\ Mirella Ghirardi, ${ }^{2}$ and Maria Concetta Miniaci ${ }^{3}$ \\ ${ }^{1}$ Neuroscience Institute Cavalieri Ottolenghi (NICO), Torino, Italy \\ ${ }^{2}$ Department of Neuroscience, University of Torino, Torino, Italy \\ ${ }^{3}$ Department of Pharmacy, University of Naples Federico II, Naples, Italy \\ ${ }^{4}$ National Institute of Neuroscience (INN), Torino, Italy \\ Correspondence should be addressed to Eriola Hoxha; eriola.hoxha@unito.it
}

Received 28 April 2017; Revised 6 July 2017; Accepted 25 July 2017; Published 15 August 2017

Academic Editor: J. Michael Wyss

Copyright (c) 2017 Eriola Hoxha et al. This is an open access article distributed under the Creative Commons Attribution License, which permits unrestricted use, distribution, and reproduction in any medium, provided the original work is properly cited.

\begin{abstract}
The formation of the complex cerebellar cortical circuits follows different phases, with initial synaptogenesis and subsequent processes of refinement guided by a variety of mechanisms. The regularity of the cellular and synaptic organization of the cerebellar cortex allowed detailed studies of the structural plasticity mechanisms underlying the formation of new synapses and retraction of redundant ones. For the attainment of the monoinnervation of the Purkinje cell by a single climbing fiber, several signals are involved, including electrical activity, contact signals, homosynaptic and heterosynaptic interaction, calcium transients, postsynaptic receptors, and transduction pathways. An important role in this developmental program is played by serotonergic projections that, acting on temporally and spatially regulated postsynaptic receptors, induce and modulate the phases of synaptic formation and maturation. In the adult cerebellar cortex, many developmental mechanisms persist but play different roles, such as supporting synaptic plasticity during learning and formation of cerebellar memory traces. A dysfunction at any stage of this process can lead to disorders of cerebellar origin, which include autism spectrum disorders but are not limited to motor deficits. Recent evidence in animal models links impairment of Purkinje cell function with autism-like symptoms including sociability deficits, stereotyped movements, and interspecific communication by vocalization.
\end{abstract}

\section{Introduction}

The neuronal architecture of the mature nervous system is reached through complex processes of synaptic rearrangement during pre- and early postnatal life. This process is established by a genetic program and is then refined by experience, activity, and molecular cues. During this critical period, the developing brain displays an extraordinary degree of plasticity and undergoes an extensive refinement of the neuronal network consisting in the removal of redundant inputs (synapse elimination) and strengthening of the remaining ones (for review see [1-3]). The cerebellum represents an attractive model to study the cellular and molecular mechanisms that underlie neural remodeling in the developing brain. Even subtle defects in this process are responsible for disorders due to improper signaling in the cerebellar neuronal network, ranging from symptoms belonging to the autism spectrum to classical ataxic motor deficits. A high degree of plasticity is retained in mature cerebellar circuits. Such adult synaptic rearrangements are essential for a continuous updating and refinement of data processing, which are the basis of cerebellar learning and memory.

\section{Structural Plasticity in the Developing Cerebellum}

In the adult cerebellar cortex, parallel fibers $(\mathrm{PF})$, originating from granule cells, establish more than 100,000 synapses on 
the distal dendritic compartment of Purkinje cells (PC) while each $\mathrm{PC}$ is innervated on the proximal dendritic domain by a single climbing fiber (CF), which is an axonal branch of an inferior olivary neuron $[4,5]$. This exclusive projection is achieved during development by drastically reducing the number and reshaping the distribution of the olivocerebellar CFs. At birth, each PC receives innervation by multiple CFs with similar synaptic strength [6-8]. These redundant CFs are eliminated during the second and third postnatal weeks, attaining monoinnervation by postnatal day 20 (P20) in mice (for review, see [9-11]). The single predominant CF forms hundreds of excitatory synapses, whose activation evokes, in PC dendrites, a strong depolarization and a pronounced increase in intradendritic calcium concentration, mediated by voltage-dependent $\mathrm{Ca}^{2+}$ channels (VDCCs) of the P/Q type [12-16].

The development of CFs has been classified in several stages $[17,18]$, starting from the "creeper" stage (P0), in which CFs crawl among PC somata to form transient synapses on immature dendrites, followed by the "pericellular nest" stage (P5) during which CFs display a high synaptogenic activity on PC somata. Then, CF innervation is displaced to the apical portion of PC somata in the "capuchon" stage (P9) and translocates to the dendrites in the "dendritic" (P12) stage. In parallel with the removal of CF synaptic terminals on the PC soma, GABAergic synapses from basket cells and stellate cells are massively formed on PCs [19-21].

As the PC dendritic arbor develops, the CF-PC connection is refined with the extension of a few CFs and the retraction of the others with the final outcome of a single winner $\mathrm{CF}$ and the complete withdrawal and disappearance of all the others. This process consists of at least two distinct phases, an earlier phase up to P7 where multiple CFs establish their synapses onto the PC and a later phase from P7 to P21, in which all CFs except one are eliminated [22-25]. The strength of different CFs in a single PC starts to diverge already in the early phase, indicating that an ongoing competition between CFs already started at this time [23]. While the early phase is independent of PF-PC synapse $[11,26]$, the later phase requires normal PF-PC synaptic transmission $[11,26]$ and involves heterosynaptic and homosynaptic mechanisms of CF elimination [7, 8, 22, 26-29]. The early phase of CF development is also influenced by the patterns of olivary activity, as shown by persistence of multiple CFs in PCs until at least 3 months of age following administration of harmaline, which abnormally synchronizes olivary neuron activity [30]. Postsynaptic activity also plays a role in this process: reducing PC excitability by expression of a recombinant chloride channel during the second postnatal week prolongs CF multiple innervation until adulthood [31].

A critical role of the P/Q-type VDCCs has been reported in CF homosynaptic competition leading to selective strengthening of single CF inputs, promotion of dendritic translocation of the strengthened CFs, and subsequent CF synapse elimination $[15,32,33]$. Mice with a selective deletion of Cav2.1 in PCs show an impaired heterosynaptic competition between PFs and CFs on PCs, which leads to hyperspiny transformation and chaotic innervation by multiple CFs and numerous PFs in proximal somatodendritic domains of PCs, and progressive degeneration of PCs [16]. A similar disruption of synaptic wiring is also induced by chronic blockade of neuronal activity by tetrodotoxin (TTX) and of AMPA receptors by NBQX in mature cerebellum [34-36]. In addition, Kakizawa et al. [37] reported that CF synapse elimination from P8 to P12 is modulated by local application of insulin-like growth factor I, suggesting that IGF-1 may provide a trophic support to maintain CF synapses. While the early phase of CF elimination is mainly driven by homosynaptic competition, in the late-phase of CF elimination, heterosynaptic regulations by PFs and GABAergic synapses have a crucial role.

The formation and maintenance of the PF-PC synapse is modulated by the GluD2 receptor (previously called GluR $\delta 2$ $[38,39])$ that is selectively expressed at this synapse but not at the CF synapse $[40,41]$ and has a specific site of interaction (the N-terminal domain) with the presynaptic neurexin via the synaptic organizer Cbln1 [42-44]. GluD2 belongs to ionotropic glutamate receptors but it is not gated by glutamate. The gate of GluD2 has been shown to be opened by activation of the type 1 metabotropic glutamate $\left(\mathrm{mGlu}_{1}\right)$ receptor $[45,46]$. D-Serine released from astrocytes also binds to GluD2, with an inhibitory effect on LTD induction [47]. During development, GluD2 is involved in the stabilization and strengthening of the synaptic connection between PFs and PCs [48-50].

Mutant mice deficient in the GluD2 receptor $[28,29]$ exhibit impaired formation and stabilization of PF-PC synapses and abnormalities in CF innervation patterns with multiple CF innervation not only around the PC soma but also in PC distal dendrites where PFs normally form synapses. The aberrant dendritic innervation was also observed in the mice with hypogranular cerebellum generated by methylazoxy methanol acetate treatment [51] and in mutant mice deficient in Cbln1 [42] that binds to GluD2 and stabilizes PF-PC synapses.

The impairment of the late phase of CF synapse elimination has also been observed in mice deficient in the $\mathrm{mGlu}_{1}$ receptor-G $\alpha \mathrm{q}-\mathrm{PLC} \beta 4-\mathrm{PKC} \gamma$ signaling cascade in PCs [52-57] and after chronic blockade of cerebellar NMDA receptors $[58,59]$.

GABAergic inhibition is also crucial for CF synapse elimination as reported by Nakayama et al. [60] in mice with a heterozygous deletion of the GABA-synthesizing enzyme GAD67 that results in a reduced activation of $\mathrm{GABA}_{\mathrm{A}}$ receptors within the cerebellum. The association of CF synapse elimination and alteration in GABAergic transmission has also been revealed in TrkB-deficient mice [61-65].

Elimination of redundant climbing fibers to PC synapses in the developing cerebellum is also regulated by retrograde signals from postsynaptic cells, such as semaphorin $3 \mathrm{~A}$ and semaphorin7A $[66,67]$. Indeed, the knockdown of Sema3A in PCs or its coreceptor, plexinA4, in CFs accelerated CF synapse elimination and decreased CF-mediated synaptic inputs. Conversely, knockdown in PCs of Sema7A or in CFs of either of the two receptors for Sema7A, plexinC1, and integrinB1 impaired CF synapse elimination (Figure 1). Importantly, the effects of Sema7A involve the activation of $\mathrm{mGlu}_{1}$ signaling, which is likely involved in the late stage of CF synapse elimination. 


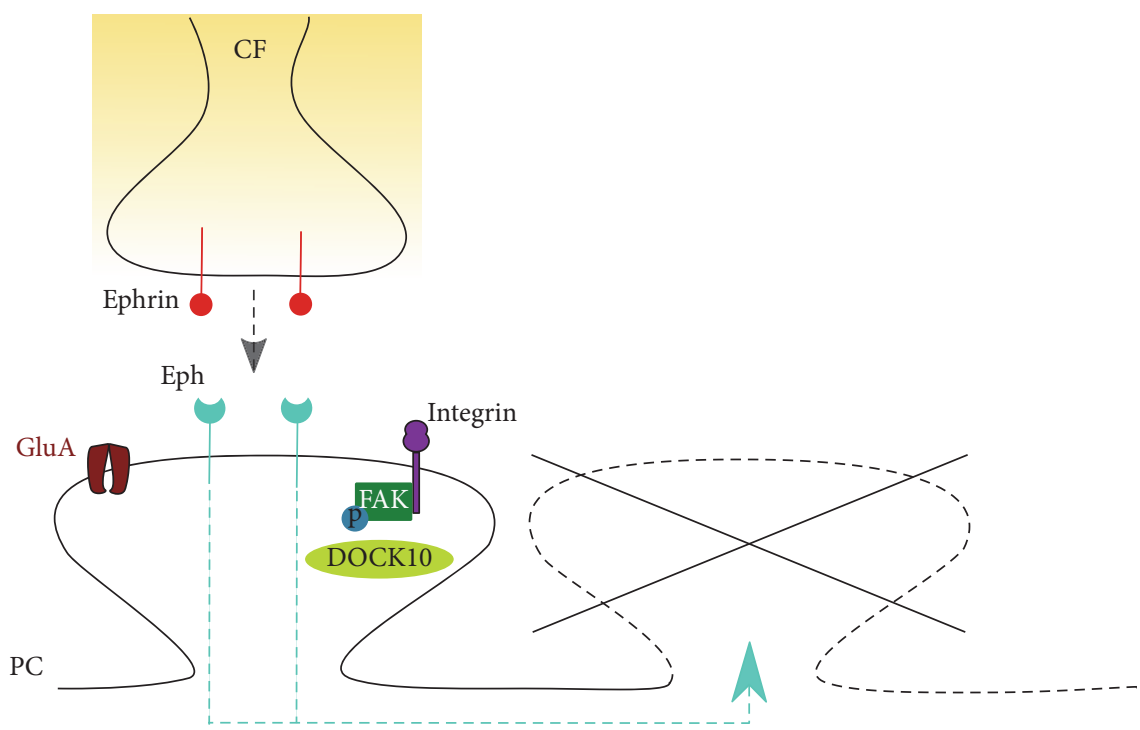

(a)
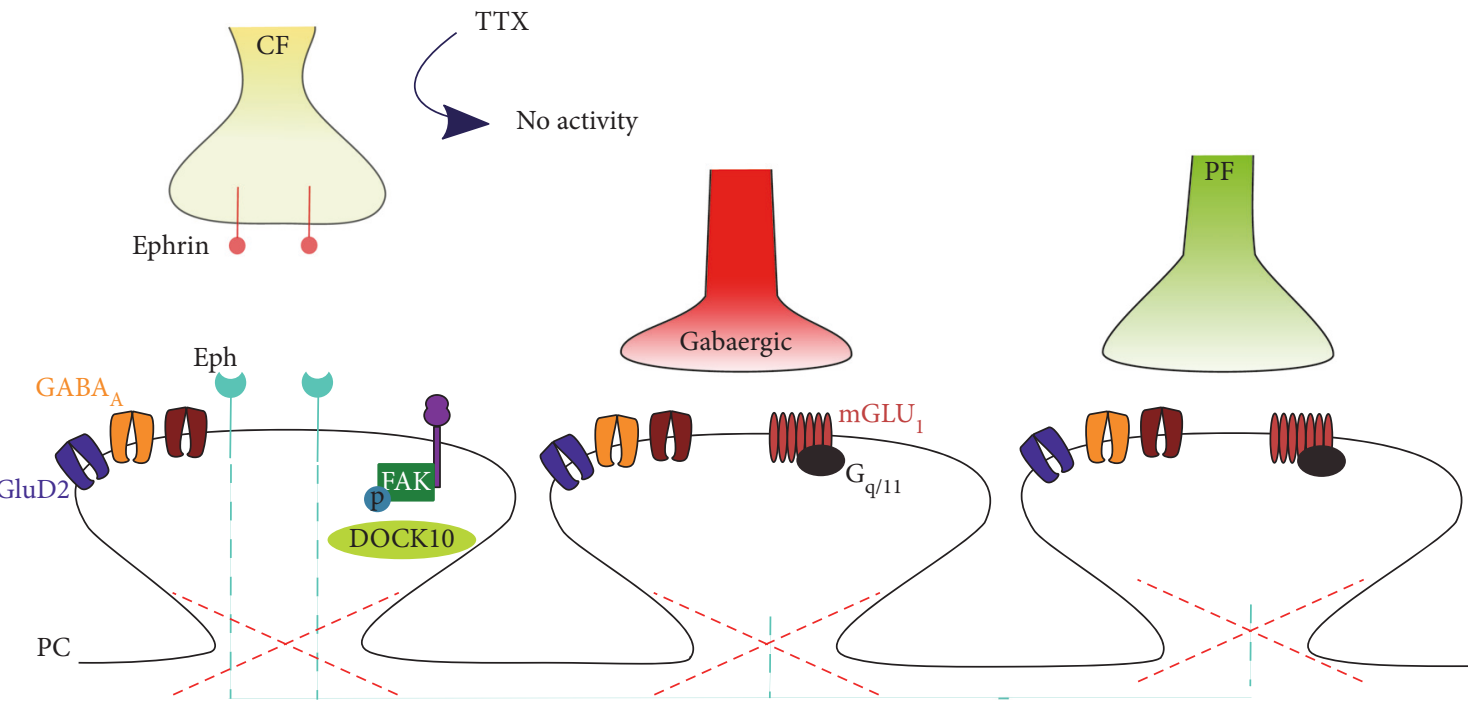

(b)

FIGURE 1: (a) Schematic model of the mechanisms of the ephrin pathway in the control of CF-induced spine regulation in mature cerebellar PCs (see text). (b) The block of activity induces proliferation of spines expressing GluD2 and GABA receptors, atrophy and loss of contacts of the $\mathrm{CF}$, and expansion of the PFs and GABAergic terminals to the proximal domain of PCs.

Therefore, in the first 3 weeks of postnatal development in rodents, homosynaptic competition among CFs, heterosynaptic competition between $\mathrm{CFs}$ and $\mathrm{PFs}$, and retrograde signals from the PC promote the maturation of PC circuitry in the cerebellar cortex, with strict territorial innervation by $\mathrm{CFs}$ and PFs and monoinnervation of PCs by CFs.

\section{Structural Remodeling in the Mature Cerebellar Cortex}

The structural plasticity that allows the formation of the highly organized excitatory wiring in early postnatal development is remarkably well maintained in the mature cerebellar cortex. In the mature cortex, PCs also receive a strong inhibitory GABAergic input from basket and stellate neurons, which are distributed along the PC's somatodendritic region.
The proximal dendritic compartment of PCs has a very low number of spines, which are organized in clusters and postsynaptic to CF varicosities, while the distal compartment is contacted by thousands of PFs and has a very high spine density (spiny branchlets) [4]. In the mature PC, GluD2 receptors are selectively localized in dendritic spines postsynaptic to PFs $[41,68]$.

Structural changes of PC dendritic spines represent a fundamental aspect of the mature cerebellar cortex plasticity. Dendritic spines are considered the major loci of synaptic plasticity in the brain and therefore the structural substrate of memory [69-74]. Several studies showed that dendritic spines are highly dynamic structures, which can change their shape and size. In response to electrical and chemical stimuli, dendritic spines can be retracted or can be generated anew. This extraordinary plasticity is present throughout life, 
suggesting that the dynamic assembly of spines is essential for normal brain function [75-82]. In different brain regions, the rate of spine turnover is modulated by sensory experiences and learning [83-85] and altered in some pathological states including autism and depression [86-90]. Several evidences show that spine growth can be induced by presynaptic terminals or they can form by intrinsic mechanisms, as occuring in PCs $[69,91,92]$.

The two main excitatory inputs, CF and PF fibers, that contact the proximal and distal domains, respectively, of the PC dendrites compete to keep their innervation territory during development and in adulthood. This competition appears to be regulated by activity and determines and maintains the adult phenotype of PCs. Studies in adult rats have demonstrated that a few days after a subtotal lesion of the inferior olivary neurons induced by 3 -acetylpyridine, the surviving CFs are able to sprout and reinnervate the denervated PCs $[93,94]$ while a large number of new spines emerge from the PC's proximal dendritic domain accompanied by sprouting of nearby located PFs $[95,96]$. This indicates that, as one of the two inputs is weakened, the other one takes over the territory left. Interestingly, GluD2 receptors appear in the newly formed spines innervated by PFs and CFs [97]. Reactive $\mathrm{PC}$ hyperspinogenesis and synaptogenesis by the PF input have also been reported following lesion of olivocerebellar axons [98].

After PC degeneration induced by kainic acid or propidium iodide or by genetic mutations, CFs progressively undergo remarkable regressive modifications with the disappearance of most of their terminal arborisation [99, 100]. However, these structural and functional changes are reversed whenever embryonic PCs are transplanted into a kainic acid lesioned or into a mutant cerebellar cortex [96, 101-104].

Blocking electrical activity in adult cerebellar cortex by infusing TTX or a selective AMPA receptor antagonist induces the loss of a large number of synaptic contacts of CF terminal arbors, the expansion of the PF territory which invade the proximal dendritic domain of PCs, and the appearance of a high number of new spines in PC proximal dendrites $[34,36,97,98]$ that express GluD2 receptors. Interestingly, this receptor is also expressed in spines innervated by GABAergic neurons and in those still in contact with the $\mathrm{CF}$, suggesting that GluD2 expression is an intrinsic activity-independent property of all PC spines that is independent from the type of afference [105]. The changes were reversible upon removal of the TTX block $[34,105]$. These findings led to the hypothesis that the CF exerts an activitydependent spine-pruning action with downregulation of GluD2 expression in its own spines at the proximal dendrites around its synapses as a kind of lateral inhibition $[97,106]$ through ionotropic AMPA/kainate receptors [36].

After the block of electrical activity, the density of GABAergic terminals is significantly increased only in the PC proximal domain [107] with the appearance of asymmetric spine synapses expressing $\mathrm{GABA}_{\mathrm{A}}$ receptor subunits in addition to glutamate receptors and GluD2 subunits. These observations suggest that the competition for the innervation of PCs is not limited to the two excitatory inputs but the activity of the $\mathrm{CF}$ also has a fundamental role in the maintenance of the proper synaptic excitatory and inhibitory architectural wiring.

The repression of spine proliferation induced by CF activity in PC proximal dendrites may be mediated by Eph receptor signaling [108], a pathway that plays an important role in dendritic spine formation and maintenance [109-112]. Cesa et al. [108] showed that the inhibition of both ephrin A and ephrin $B$ induced a rapid proliferation of spines in the proximal dendrite, while infusion of ephrin A2 or ephrin B1 partially suppressed the proliferation of proximal spines that occurs when CF electrical activity is blocked in vivo by TTX. Interestingly, animals lacking ephB1, B2, and B3 exhibited a significantly high spine density in the PC proximal dendrite despite the presence of CFs, suggesting that one or more of these receptors is the target on PCs for ephrins released from the CFs.

Jaudon et al. [113] suggested that among the possible downstream targets of Eph receptors in the cerebellum, there are the members of the DOCK family of RhoGEFs such as the Cdc42-specific GEF DOCK10. They found that DOCK10 protein expression increased during PC development whereas depletion of DOCK10 in PCs leads to dendritic spine defects. In addition, they reported that DOCK10 is essential for spine formation, not only in PCs but also in cultured hippocampal neurons. Interestingly, a human genetics study showed that deletion of the DOCK10 gene is associated with autism spectrum disorders [114] characterized by developmental alterations of spines and loss of synaptic plasticity.

Recently Heintz et al. [115] suggested that Eph/ephrin signaling regulates proximal dendritic spines in PCs by inactivating integrin downstream signaling, that is, known to be involved in spine formation, stability, motility, and morphology [82, 116-119]. In mixed cerebellar cultures deprived of CFs, they demonstrated that Ephrin A3 inhibits integrin activity in proximal dendritic spines and induces a collapse of proximal but not distal spines, similar to the effect of CFs, which is prevented by integrin activation.

These findings suggest an interesting mechanism action by which CFs can shape the proximal dendrites of PCs and remodel the spine distribution, from the numerous small spines typical of distal dendrites to the few large spines that contact CFs. This process is likely regulated by ephrin, which is released either by the $\mathrm{CF}$ or by perisynaptic astrocytes. Ephrin acts on EphA4 on PC dendrites, leading to a signaling process, restricted to the proximal dendrites, that inactivates integrins or focal adhesion kinase (FAK) in the spines, causing spine retraction (Figure 1) [115].

\section{The Role of the Serotonergic System in the Development, Maturation, and Refinement of Cerebellar Synaptic Networks}

Considerable evidence supports the idea that serotonin (5-HT) acts as a regulator of brain development and contributes to the refinement of neuronal circuitry during the critical periods of early postnatal life [120-124]. Alterations of the 5-HT system during early development are considered 


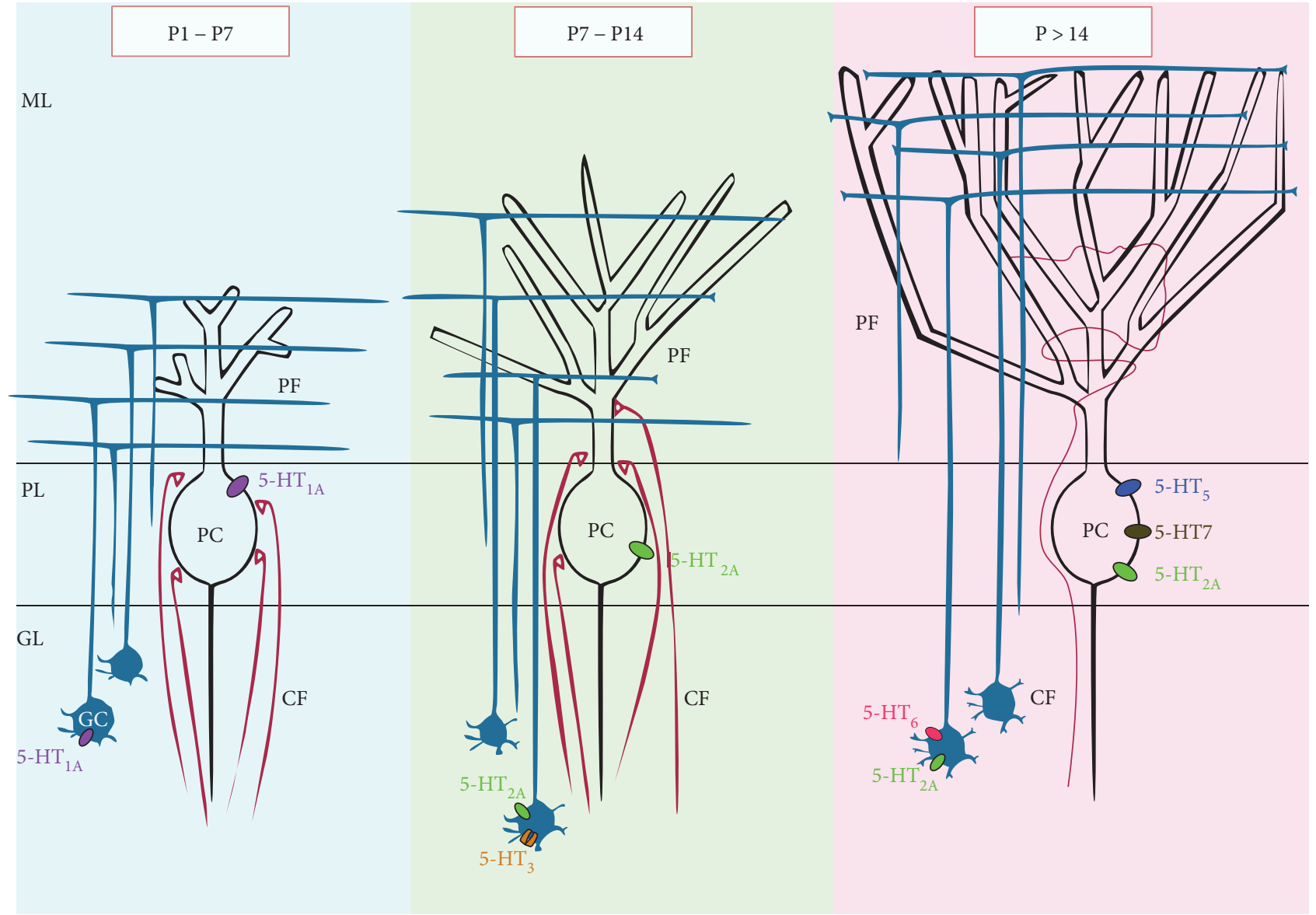

Figure 2: Schematic representation of the 5-HT receptor subtypes expressed by PCs and granule cells (GCs) during the different stages of postnatal cerebellar development. GL: granular layer; PL: Purkinje cell layer; ML: molecular layer.

to play a critical role in the etiology of neurodevelopmental disorders such as autism and schizophrenia $[125,126]$.

Serotonergic projections to the cerebellum develop during the postnatal period in coincidence with the perinatal development of the cerebellar cortex [127]. Developmental events such as PC maturation, climbing fiber elimination, and granule cell migration are orchestrated processes that are likely modulated by the 5-HT system.

The variety of 5-HT effects in developmental processes is mediated by different types of 5-HT receptors (5-HTR), each with its spatial and temporal expression pattern [128, 129]. Thus by far, 14 subtypes of 5-HTRs have been identified and classified into seven families and designed $5-\mathrm{HT}_{1} \mathrm{R}$ through $5-\mathrm{HT}_{7} \mathrm{R}$, based upon their structure and pharmacological profile. Six of the families $\left(5-\mathrm{HT}_{1,2,4-7}\right)$ are members of the G-protein-coupled receptor superfamily, whereas $5-\mathrm{HT}_{3}$ belongs to the superfamily of ligand-gated ion channels [130].

The expression of 5-HTR subtypes and therefore the effects of 5-HT in the developing cerebellum vary with the stage of cell differentiation [131-133] (Figure 2). In particular, $5-\mathrm{HT}_{1 \mathrm{~A}}$ Rs are transiently expressed by cerebellar granule cells during the first 2 weeks and no expression is detected in adult rodents [134]. On the other hand, $5-\mathrm{HT}_{2 \mathrm{~A}} \mathrm{Rs}$ are expressed on granule cells late in development: expression of $5-\mathrm{HT}_{2 \mathrm{~A}} \mathrm{Rs}$ starts from $\mathrm{P} 5$, increases dramatically at the second postnatal week, and remains sustained, at a lower level, until 10 weeks of age. In PC, the time course of expression of $5-\mathrm{HT}_{1 \mathrm{~A}}$ and $5-\mathrm{HT}_{2}$ receptors is almost similar to that of granule cells. The $5-\mathrm{HT}_{1 \mathrm{~A}} \mathrm{R}$ is detected on PCs only in the first postnatal week. $5-\mathrm{HT}_{2 \mathrm{~A}} \mathrm{R}$ appears in the PC soma shortly after birth and increases first in the proximal dendrites of PCs at $\mathrm{P} 6-\mathrm{P} 10$ and then in proximal and distal dendrites after $\mathrm{P} 12$, where it is maintained in adulthood [135]. $5-\mathrm{HT}_{1 \mathrm{~A}}$ and $5-\mathrm{HT}_{2 \mathrm{~A}}$ receptors have different effects on the development of PC dendrites. Studies in vitro have demonstrated that 5-HT promotes dendritic growth of PCs through $5-\mathrm{HT}_{1 \mathrm{~A}} \mathrm{Rs}$, while $5-\mathrm{HT}_{2 \mathrm{~A}} \mathrm{Rs}$ inhibit the dendritic development of PC [136]. These data are in accordance with other in vivo and in vitro studies showing an important role of 5-HT in dendritic development, formation of dendritic spines, and synapse formation in the cerebral cortex and hippocampus [137].

Expression of $5-\mathrm{HT}_{3}$ receptors has been observed in granule cells of the cerebellum within the first three postnatal weeks in rodents with relatively high expression in lobules I-VI and to a lesser extent in lobules VII-X $[138,139]$. Studies in $5-\mathrm{HT}_{3 \mathrm{~A}} / \mathrm{EGFP}$ transgenic mice have revealed that the expression pattern of $5-\mathrm{HT}_{3} \mathrm{R}$ at $\mathrm{P} 7$ follows the migration pathway of the cerebellar granule cells from the external to the internal granule cell layer; then, by P14, the expression 
starts to decrease and becomes completely absent after P21 [138]. In contrast, no coexpression of $5-\mathrm{HT}_{3}$ receptors has been found with glial cells, PCs, and interneurons. Patch clamp recordings from granule cells of $5-\mathrm{HT}_{3 \mathrm{~A}} \mathrm{R} / \mathrm{EGFP}$ transgenic mice indicated that $5-\mathrm{HT}_{3}$ receptors are in a functional state at P6-P10, since application of a selective $5-\mathrm{HT}_{3}$ receptor agonist induced a fast inward current. At the same age, functional $5-\mathrm{HT}_{3}$ receptors appear also at the presynaptic site of the PF-PC synapse, where they modulate short-term synaptic plasticity and eventually the maturation of these synapses. Interestingly, the time window of $5-\mathrm{HT}_{3}$ receptor expression corresponds to the period during which PC dendrites develop [140]. The involvement of $5-\mathrm{HT}_{3}$ receptors in controlling the morphological maturation of PCs has been clearly demonstrated by Oostland et al. [139] in slices of $5-\mathrm{HT}_{3 \mathrm{~A}} \mathrm{R}$ knockout mice at P9 and in organotypic slice cultures treated at $\mathrm{P} 8$ with a $5-\mathrm{HT}_{3} \mathrm{R}$ antagonist. In both models, PCs show a higher dendritic length and complexity with respect to the control condition. In addition, 5- $\mathrm{HT}_{3} \mathrm{R}$ knockout animals show delayed $\mathrm{CF}$ elimination from P7 to P24, whereas no difference in the number of climbing fibers innervating one Purkinje cell was observed at P5 and P6 compared to controls. Morphology and physiology of PCs in $5-\mathrm{HT}_{3} \mathrm{R}$ knockout mice appear normal in adult mice. This suggests that $5-\mathrm{HT}_{3} \mathrm{Rs}$ regulate the maturation of the cerebellar circuitry during a specific time window when heterosynaptic competition between parallel fibers and climbing fibers occurs.

Based on the different temporal expression pattern of these 5-HTR subtypes, it has been argued that, during the first postnatal week, activation of $5-\mathrm{HT}_{1}$ Rs expressed by both granule cells and PCs promotes PC dendritic growth [139]. Later activation of $5-\mathrm{HT}_{3}$ Rs expressed by granule cells limits dendritic growth of PCs and controls the $\mathrm{CF}$ elimination from PC dendrites. Last, $5-\mathrm{HT}_{2} \mathrm{Rs}$ expressed by granule cells and PCs determine inhibition of PC dendritic growth and promote synaptic activity stability.

Anatomical and pharmacological studies indicate that the cerebellar cortex expresses additional subtypes of 5-HTRs in both the developing and adult cerebellum. For example, $5-\mathrm{HT}_{5}$ and $5-\mathrm{HT}_{7}$ subtypes have also been found on PCs, whereas $5-\mathrm{HT}_{6} \mathrm{Rs}$ are expressed on granule cells [141-144]. Expression of $5-\mathrm{HT}_{5 \mathrm{~A}} \mathrm{R}$ has also been found on Golgi cells and molecular layer interneurons $[134,142]$.

The cerebellar widespread projection of 5-HT fibers and the variety of 5-HT receptors allow the 5-HT system to differentially modulate both excitatory and inhibitory synaptic transmission throughout the entire cerebellar cortex until adulthood $[145,146]$. Indeed, studies in vitro have demonstrated that application of 5-HT facilitates the GABAergic transmission between cerebellar interneurons (i.e., basket, stellate, and Lugaro cells) and PCs [147, 148] but reduces the release of the excitatory transmitter glutamate from PFs onto PCs [149]. This suggests that 5-HT determines an overall depression of PC activity via suppression of excitatory inputs from PFs and facilitation of inhibitory inputs from interneurons. Such mechanism can potentially decrease the inhibitory drive of PCs to deep cerebellar nuclei neurons and ultimately refine the motor output.
Lippiello et al. [144] have recently demonstrated that in adult mice, 5-HT also exerts a fine regulation of synaptic plasticity at the PF-PC synapse via $5-\mathrm{HT}_{7} \mathrm{Rs}$, without affecting the CF-PC synaptic transmission. Indeed, the selective activation of $5-\mathrm{HT}_{7} \mathrm{R}$ by LP-211 caused, on one hand, LTD of the PF-PC synapse and, on the other hand, impaired LTP at the same synapse. Moreover, bath application of a $5-\mathrm{HT}_{7} \mathrm{R}$ antagonist prevented LTD produced by pairing PF stimulation with PC depolarization. The suppressive effect of LP-211 on LTP induction can be considered an important mechanism to prevent the simultaneous occurrence of conflicting forms of plasticity, such as potentiation of synaptic transmission under conditions that promote postsynaptic LTD. The combination of LTP and LTD is believed to underlie several forms of motor learning [150]. The involvement of serotonin in motor learning has been observed in several cerebellar-dependent paradigms. For example, depletion of brain 5-HT has been shown to impair adaptation of the horizontal vestibulo-ocular reflex (VOR) in rabbits [151]. On the other hand, activation of 5-HTR improves motor coordination deficits in patients with inherited or acquired ataxia.

\section{Cerebellar Network Maturation and Refinement in Autism Spectrum Disorders}

Autism spectrum disorders (ASD) are characterized by deficits in social interaction, impaired communication, repetitive behaviors, and restricted interests [152]. In the last decades, it has been recognized that most cases of ASD are associated with cerebellar malformations (for review, see [153]). The loss of PCs is the single most frequent finding at autopsy of subjects with ASD [154, 155]. Recent studies in animal models of ASD have clearly shown that the cerebellar cortex is a pivotal structure in the pathogenesis of autism. The experimental strategies of these studies include selective gene deletion in cerebellar PCs [156-158] and reversal of autistic symptoms by re-expression, in PCs, of a wild-type gene [159].

The PC-selective deletion of the Tscl gene $\left(T s c 1^{P C}\right)$ in mice reproduces the core symptoms of autism that in this animal species are displayed as impairment of sociability, repetitive grooming behavior, and deficit of vocalization [156]. While homozygous $T s c 1^{P C}$ mice also display PC loss and motor symptoms, heterozygous ones display ASD symptoms without other accompanying signs. In such heterozygous $T s c 1^{P C}$ mice, PCs have a normal overall morphology but show increased PC spine density, which is in line with the frequent finding of hyperspiny neurons in ASD patients [160]. This feature has been attributed to a failure to complete the maturation of dendritic spines [161]. In $T s c 1^{P C}$ mice, PCs show a reduced spontaneous and evoked action potential firing, although synaptic transmission is unaltered. Although the reason of the impairment of PC firing is unknown, it might affect, via deep cerebellar nuclei, downstream cerebral networks thereby causing autistic symptoms.

A second, independent murine model of ASD was generated by selective deletion of phosphatase and tensin homolog missing on chromosome 10 (Pten) in cerebellar PCs $\left(\right.$ Pten $^{P C}$ mice) [157]. PTEN mutations are responsible 
TABLE 1

\begin{tabular}{|c|c|c|c|c|}
\hline & $T s c 1^{P C}$ & Pten $^{P C}$ & Shank $2^{P C}$ Peter et al. [158] & Shank2 ${ }^{P C} \mathrm{Ha}$ et al. [165] \\
\hline \multicolumn{5}{|l|}{ Structural features } \\
\hline Soma & Normal & Hypertrophic & Normal & \\
\hline Dendrites & n.a. & Hypertrophic & Normal & \\
\hline Spines & Increased & n.a. & Normal & \\
\hline Axon & Varicosities & Varicosities & n.a. & \\
\hline \multicolumn{5}{|l|}{ Functional features } \\
\hline spont. firing & Decreased & Decreased & Normal frequency, increased irregularity & n.a. \\
\hline Excitability & Decreased & Decreased & n.a. & n.a. \\
\hline spont. EPSCs & n.a. & n.a. & n.a. & Decreased frequency \\
\hline PF-EPSCs & Normal & Hyperfunctional & Normal & n.a. \\
\hline PF-LTD & n.a. & n.a. & n.a. (but normal in the global KO) & Normal \\
\hline CF-EPSCs & Normal & Hypofunctional & Normal & n.a. \\
\hline GABAergic IPSCs & Normal & n.a. & n.a. (increased IPSC frequency in the global KO) & n.a. \\
\hline
\end{tabular}

for up to $5-10 \%$ of ASD cases [162]. PTEN has an antagonistic action on phosphatidylinositol-3-kinase (PI3K), with a negative regulation of its transduction pathways. Interestingly, the PI3K/PTEN signaling pathway regulates the TSC1/TSC2 complex and its downstream targets, including the mammalian target of rapamycin (mTOR) [163, 164]. Pten $^{P C}$ mice show PC degeneration starting at 6 months of age, but autistic-like symptoms are present before the onset of PC death. They display impaired sociability and repetitive behavior (jumping/scrabbling). PCs of Pten $^{P C}$ mice show several structural and functional abnormalities. PC soma, dendrites, and axon are enlarged, with focal dendritic swellings and axonal torpedoes. PCs of Pten ${ }^{P C}$ mice showed a lower spontaneous firing rate and reduced excitability, similar to $T s c 1^{P C}$ mice. These deficits were associated with a lower input resistance, which might be at least partially responsible for the reduced excitability. However, in contrast to $T s c 1^{P C}$, in which PC postsynaptic currents were intact, in ten $^{P C}$ mice, the excitatory postsynaptic currents (EPSCs) evoked by PF activity (PF-EPSCs) were aberrantly larger and those evoked by CF activity (CF-EPSCs) were smaller than in controls. These functional alterations might co-operate to determine improper output signals responsible for the development of autism.

A third model of ASD is the Shank2-knockout mouse $[158,165]$. Mutations of SHANK2 are associated with ASD, and SHANK2 variants in conserved amino acids are enriched in individuals with ASD [166]. Previous studies had shown that a global deletion of Shank2 causes ASD-like behaviors $[167,168]$. Shank2 is localized at the postsynaptic density and is involved in synaptic formation and refinement [165]. A PC-selective deletion of Shank2 $\left(\operatorname{Shank} 2^{P C}\right)$ has been generated by two research groups, with different results. Peter et al. [158] found that Shank2 ${ }^{P C}$ mice show deficits in social interaction. In contrast, $\mathrm{Ha}$ et al. [165] report normal sociability and vocalization and absence of repetitive behavior in their Shank $2^{P C}$ mice. In global Shank2 knockout mice, the density and morphology of PC dendritic spines were intact $[158,165]$. In contrast, in the same mice, Ha et al. [165] found a significant reduction in the number of postsynaptic densities. Both studies report a reduced expression of glutamate receptors in dendrites of global Shank2 knockout PCs, suggesting a deficit in formation and maintenance of glutamatergic synaptic contacts. On the other hand, in Shank $2^{P C}$ mice, only GluD2 (GluRD2) and PSD93 were significantly reduced [165]. Evoked PF-EPSCs had normal amplitude [158]. However, Ha et al. [165] analyzed spontaneous EPSCs in Shank $2^{P C}$ PCs and found a markedly lower frequency, in line with a reduced number of excitatory synaptic contacts. Peter et al. [158] also analyzed, but in global Shank2 knockout PCs, spontaneous GABAergic IPSCs, which were increased in frequency. The PC spontaneous firing recorded in vivo from Shank $2^{P C}$ mice had a normal frequency but a higher variability [158]. The synaptic plasticity of the PF-PC synapse was studied by Peter et al. [158] in the global knockout and by $\mathrm{Ha}$ et al. [165] in Shank2 ${ }^{P C}$ PCs. In both models, long-term depression (LTD) was preserved, while long-term potentiation (LTP) was only analyzed in the global knockout, where it was impaired [158]. It remains to be determined whether LTP is impaired also in the PC-selective knockout model. Taken together, the results on Shank $2^{P C}$ mice indicate a variable influence on autistic-like behaviors and only subtle synaptic and firing alterations. An overview of the result on these PC-selective models is reported in Table 1.

The critical periods in which the causative or risk genes produce neural functional alterations responsible for autism are not known. Studies of patients with ASD provided compelling evidence that the onset of the disease is in the first months of life, even if the diagnosis is often delayed [169]. However, gene expression studies showed that the peak of expression of the majority of risk genes converges during fetal development, while for another subset of genes, it coincides with neuronal maturation [170]. This problem has been studied in animal models by conditional gene expression utilizing inducible mutations [171]. Since ASDs are a heterogeneous class of disorders, in line of principle, it is possible that some cases are reversible even in the adult stage, while others are expected to be refractory to any kind of treatment outside a critical period in which the genetic defect triggered 
the neural alterations. The former case has been shown following deletion of Mecp2 in adult mice, which impairs the nest-building behavior, as in germinal knockouts [172]. Reactivation of Mecp2 in adulthood rescues this behavioral deficit [173]. However, it must be pointed out that in this model, no other ASD-linked behavior is altered. In contrast, in a murine model of the Angelman syndrome, which includes ASD symptoms, a rescue of Ube3a expression is only effective in embryonic age, while its re-expression during postnatal life fails to recover the autism-related behaviors [174]. In animal models of ASD caused by mutations of the synaptic gene Nrxn1 $\beta$ or Shank3, the re-expression of the defective transcript in adulthood successfully reversed the ASD-related behaviors, including impaired sociability and increased grooming $[175,176]$.

The developmental time windows, in which cerebellar functional alterations cause ASDs, are not known. It is interesting to note that a speech-language disorder caused by mutations of FOXP2 is associated with impairment of PC dendritic development. A murine model of this disease, in infantile age, presents reduced ultrasonic vocalizations $[177,178]$, an oral form of communication often compromised in ASD models. The conditional re-expression of Foxp2 in the cerebellum is sufficient to rescue this deficit [159]. Thus, also in this form of interindividual communication, the cerebellum plays a pivotal role, which in this case is critical in neonatal age. Future studies are necessary to establish the critical periods for the cerebellar induction of the various forms of ASD.

\section{Conclusions}

In spite of the regularity of the cellular and synaptic organization of the cerebellar cortex, the mechanisms by which the mature wiring is attained are very complex. For the CFPC synapse alone, multiple intrinsic and extrinsic signals are involved and interact with specific temporal and spatial patterns. The serotonergic system plays a crucial role in enabling and in fine tuning this process of synaptic organization. Recently, it has been shown that genetic modifications selectively targeted to PCs are sufficient to generate autismlike symptoms in animal models, by interfering with these delicate and complex developmental programs. In line with the important role of 5-HT in orchestrating the synaptic organization of the cerebellar cortex, the serotonergic system is also involved in autism. Indeed, $30-50 \%$ of autistic subjects show elevated blood levels of serotonin [179], which interfere with the developmental process of brain areas including cerebellum. Indeed, it has been demonstrated that pre- and postnatal exposure to abnormally high levels of the serotonergic agonist, mimicking the levels observed in autism, induced a significant decrease in the total number of dendritic spines in neurons of the dentate nucleus of rat cerebellum [180]. In addition, analysis of postmortem tissues has revealed a significant impairment in the activity of monoamine oxidases-A (MAO-A), in the cerebellum of children with autism (age 4-12 years) compared to control subjects [181]. Since monoamine oxidases (MAOs) catalyze the metabolism of monoamine neurotransmitters, a reduced
MAO-A activity will cause an increase of 5-HT level in the brain of autistic subjects. Interestingly, MAOA knockout mice exhibit increases in brain serotonin levels, as well as abnormally high fear conditioning, enhanced eye-blink conditioning, and increased LTP in the hippocampus $[182,183]$.

Future studies are necessary to better understand the mechanisms of synapse formation refinement of the cerebellar network and how inputs are compartmentalized to enable proper functioning and avoiding disorders ranging from motor control deficits to autism. Furthermore, studying the complex effects of 5-HT on synaptogenesis and establishment of cerebellar cortical networks, and the corresponding behavioral and psychiatric phenotypes, may provide new therapies for early intervention on neurodevelopmental disorders.

\section{Conflicts of Interest}

The authors declare that there is no conflict of interest regarding the publication of this paper

\section{References}

[1] C. S. Goodman and C. J. Shatz, "Developmental mechanisms that generate precise patterns of neuronal connectivity," Cell, vol. 72, pp. 77-98, 1993.

[2] Q. T. Nguyen and J. W. Lichtman, "Mechanism of synapse disassembly at the developing neuromuscular junction," Current Opinion in Neurobiology, vol. 6, no. 1, pp. 104-112, 1996.

[3] B. Terni, F. J. López-Murcia, and A. Llobet, "Role of neuronglia interactions in developmental synapse elimination," Brain Research Bulletin, vol. 129, pp. 74-81, 2017.

[4] S. L. Palay and V. Chan-Palay, Cerebellar Cortex, SpringerVerlag, New York, NY, USA, 1974.

[5] M. Ito, The Cerebellum and Neural Control, Raven Press, New York, NY, USA, 1984.

[6] F. Crepel, "Regression of functional synapses in the immature mammalian cerebellum," Trends in Neuroscience, vol. 5, pp. 266-269, 1982.

[7] F. Crepel, J. Mariani, and N. Delhaye-Bouchaud, "Evidence for a multiple innervation of Purkinje cells by climbing fibers in the immature rat cerebellum," Journal of Neurobiology, vol. 7, no. 6, pp. 567-578, 1976.

[8] M. Lohof, N. Delhaye-Bouchaud, and J. Mariani, "Synapse elimination in the central nervous system: functional significance and cellular mechanisms," Reviews in the Neurosciences, vol. 7, no. 2, pp. 85-101, 1996.

[9] K. Hashimoto and M. Kano, "Synapse elimination in the developing cerebellum," Cellular and Molecular Life, vol. 70, no. 24, pp. 4667-4680, 2013.

[10] H. Nishiyama, "Dendritic translocation of climbing fibers: a new face of old phenomenon," Cerebellum, vol. 14, no. 1, pp. 1-3, 2015.

[11] M. Watanabe and M. Kano, "Climbing fiber synapse elimination in cerebellar Purkinje cells," European Journal of Neuroscience, vol. 34, no. 10, pp. 1697-1710, 2011.

[12] A. Konnerth, J. Dreessen, and G. J. Augustine, "Brief dendritic calcium signals initiate long-lasting synaptic depression in cerebellar Purkinje cells," Proceedings of the National 
Academy of Sciences of the United States of America, vol. 89, pp. 7051-7055, 1992.

[13] W. G. Regehr and I. M. Mintz, "Participation of multiple calcium channel types in transmission at single climbing fiber to Purkinje cell synapses," Neuron, vol. 12, pp. 605-613, 1994.

[14] H. Miyakawa, V. Lev-Ram, N. Lasser-Ross, and W. N. Ross, "Calcium transients evoked by climbing fiber and parallel fiber synaptic inputs in guinea pig cerebellar Purkinje neurons," Journal of Neurophysiology, vol. 68, no. 4, pp. 1178-1189, 1992.

[15] T. Miyazaki, K. Hashimoto, H. S. Shin, M. Kano, and M. Watanabe, "P/Q-type $\mathrm{Ca}^{2+}$ channel $\alpha 1 \mathrm{~A}$ regulates synaptic competition on developing cerebellar Purkinje cells," Journal of Neuroscience, vol. 24, no. 7, pp. 1734-1743, 2004.

[16] T. Miyazaki, M. Yamasaki, K. Hashimoto et al., "Cav2.1 in cerebellar Purkinje cells regulates competitive excitatory synaptic wiring, cell survival, and cerebellar biochemical compartmentalization," Journal of Neuroscience, vol. 32, no. 4, pp. 1311-1328, 2012.

[17] S. Ramon y Cajal, Histologie du Systeme Nerveux de l'homme et des Vertebres, Vol. II, Maloine, Paris, FR, 1911.

[18] A. Chedotal and C. Sotelo, "Early development of the olivocerebellar projections in the fetal rat using CGRPimmunocytochemistry," European Journal of Neuroscience, vol. 4, pp. 1159-1179, 1992.

[19] R. Ichikawa, M. Yamasaki, T. Miyazaki et al., "Developmental switching of perisomatic innervation from climbing fibers to basket cell fibers in cerebellar Purkinje cells," Journal of Neuroscience, vol. 31, no. 47, pp. 16916-16927, 2011.

[20] C. Sotelo, "Development of "Pinceaux" formations and dendritic translocation of climbing fibers during the acquisition of the balance between glutamatergic and $\gamma$-aminobutyric acidergic inputs in developing Purkinje cells," Journal of Comparative Neurology, vol. 506, no. 2, pp. 240-262, 2008.

[21] I. Sugihara, "Microzonal projection and climbing fiber remodeling in single olivocerebellar axons of newborn rats at postnatal days 4-7," Journal of Comparative Neurology, vol. 487, no. 1, pp. 93-106, 2005.

[22] K. Hashimoto, R. Ichikawa, K. Kitamura, M. Watanabe, and M. Kano, "Translocation of a "winner" climbing fiber to the Purkinje cell dendrite and subsequent elimination of "losers" from the soma in developing cerebellum," Neuron, vol. 63, no. 1, pp. 106-118, 2009.

[23] K. Hashimoto and M. Kano, "Functional differentiation of multiple climbing fiber inputs during synapse elimination in the developing cerebellum," Neuron, vol. 38, no. 5, pp. 785-796, 2003.

[24] K. Hashimoto and M. Kano, "Postnatal development and synapse elimination of climbing fiber to Purkinje cell projection in the cerebellum," Neuroscience Research, vol. 53, no. 3, pp. 221-228, 2005.

[25] L. W. Bosman, H. Takechi, J. Hartmann, J. Eilers, and A. Konnerth, "Homosynaptic long-term synaptic potentiation of the "winner" climbing fiber synapse in developing Purkinje cells," Journal of Neuroscience, vol. 28, no. 4, pp. 798-807, 2008.

[26] F. Crepel, N. Delhaye-Bouchaud, and J. L. Dupont, "Fate of the multiple innervation of cerebellar Purkinje cells by climbing fibers in immature control, $\mathrm{X}$-irradiated and hypothyroid rats," Brain Research, vol. 227, no. 1, pp. 59-71, 1981.

[27] B. Scelfo and P. Strata, "Correlation between multiple climbing fibre regression and parallel fibre response development in the postnatal mouse cerebellum," European Journal of Neuroscience, vol. 21, no. 4, pp. 971-978, 2005.

[28] K. Hashimoto, R. Ichikawa, H. Takechi et al., "Roles of glutamate receptor $\delta 2$ subunit $(\mathrm{GluR} \delta 2)$ and metabotropic glutamate receptor subtype 1 (mGluR1) in climbing fiber synapse elimination during postnatal cerebellar development," Journal of Neuroscience, vol. 21, no. 24, pp. 97019712, 2001.

[29] R. Ichikawa, T. Miyazaki, M. Kano et al., "Distal extension of climbing fiber territory and multiple innervation caused by aberrant wiring to adjacent spiny branchlets in cerebellar Purkinje cells lacking glutamate receptor $\delta 2$," Journal of Neuroscience, vol. 22, no. 19, pp. 8487-8503, 2002.

[30] P. R. Andjus, L. Zhu, R. Cesa, D. Carulli, and P. Strata, "A change in the pattern of activity affects the developmental regression of the Purkinje cell polyinnervation by climbing fibers in the rat cerebellum," Neuroscience, vol. 121, pp. 563-572, 2003.

[31] E. Lorenzetto, L. Caselli, G. Feng et al., "Genetic perturbation of postsynaptic activity regulates synapse elimination in developing cerebellum," Proceedings of the National Academy of Sciences of the United States of America, vol. 106, pp. 16475-16480, 2009.

[32] K. Hashimoto, M. Tsujita, T. Miyazaki et al., "Postsynaptic $\mathrm{P} / \mathrm{Q}$-type $\mathrm{Ca}^{2+}$ channel in Purkinje cell mediates synaptic competition and elimination in developing cerebellum," Proceedings of the National Academy of Sciences of the United States of America, vol. 108, no. 24, pp. 99879992, 2011.

[33] M. Kano and K. Hashimoto, "Activity-dependent maturation of climbing fiber to Purkinje cell synapses during postnatal cerebellar development," Cerebellum, vol. 11, no. 2, pp. 449450, 2012.

[34] M. Bravin, L. Morando, A. Vercelli, F. Rossi, and P. Strata, "Control of spine formation by electrical activity in the adult cerebellum," Proceedings of the National Academy of Sciences of the United States of America, vol. 96, pp. 1704-1709, 1999.

[35] S. Kakizawa, T. Miyazaki, M. Iino, M. Watanabe, and M. Kano, "Maintenance of presynaptic function by AMPA receptor-mediated excitatory postsynaptic activity in adult brain," Proceedings of the National Academy of Sciences of the United States of America, vol. 102, pp. 19180-19185, 2005.

[36] R. Cesa, B. Scelfo, and P. Strata, "Activity-dependent presynaptic and postsynaptic structural plasticity in the mature cerebellum," Journal of Neuroscience, vol. 27, pp. 4603-4611, 2007.

[37] S. Kakizawa, K. Yamada, M. Iino, M. Watanabe, and M. Kano, "Effects of insulin-like growth factor I on climbing fibre synapse elimination during cerebellar development," European Journal of Neuroscience, vol. 17, no. 3, pp. 545-554, 2003.

[38] N. Kashiwabuchi, K. Ikeda, K. Araki et al., "Impairment of motor coordination, Purkinje cell synapse formation, and cerebellar long-term depression in GluR $\delta 2$ mutant mice," Cell, vol. 81, no. 2, pp. 245-252, 1995.

[39] T. Takeuchi, T. Miyazaki, M. Watanabe, H. Mori, K. Sakimura, and M. Mishina, "Control of synaptic connection by glutamate receptor $\delta 2$ in the adult cerebellum," Journal of Neuroscience, vol. 25, pp. 2146-2156, 2005.

[40] C. Takayama, S. Nakagawa, M. Watanabe, M. Mishina, and Y. Inoue, "Light- and electron-microscopic localization of the glutamate receptor channel $\delta 2$ subunit in the mouse Purkinje cell," Neuroscience Letters, vol. 188, pp. 89-92, 1995. 
[41] S. Landsend, M. Amiry-Moghaddam, A. Matsubara et al., "Differential localization of $\delta$ glutamate receptors in the rat cerebellum: coexpression with AMPA receptors in parallel fiber-spine synapses and absence from climbing fiber-spine synapses," Journal of Neuroscience, vol. 17, pp. 834-842, 1997.

[42] H. Hirai, Z. Pang, D. Bao et al., "Cbln1 is essential for synaptic integrity and plasticity in the cerebellum," Nature Neuroscience, vol. 8, no. 11, pp. 1534-1541, 2005.

[43] K. Matsuda, E. Miura, T. Miyazaki et al., "Cbln1 is a ligand for an orphan glutamate receptor $\delta 2$, a bidirectional synapse organizer," Science, vol. 328, no. 5976, pp. 363-368, 2010.

[44] T. Uemura, S. J. Lee, M. Yasumura et al., "Trans-synaptic interaction of GluR $\delta 2$ and neurexin through Cbln1 mediates synapse formation in the cerebellum," Cell, vol. 141, no. 6, pp. 1068-1079, 2010.

[45] V. Ady, J. Perroy, L. Tricoire et al., "Type 1 metabotropic glutamate receptors (mGlu1) trigger the gating of GluD2delta glutamate receptors," EMBO Reports, vol. 15, no. 1, pp. 103109, 2014.

[46] S. Dadak, N. Bouquier, E. Goyet, L. Fagni, C. Levenes, and J. Perroy, "mGlu1 receptor canonical signaling pathway contributes to the opening of the orphan GluD2 receptor," Neuropharmacology, vol. 115, pp. 92-99, 2017.

[47] W. Kakegawa, Y. Miyoshi, K. Hamase et al., "D-serine regulates cerebellar LTD and motor coordination through the $\delta 2$ glutamate receptor," Nature Neuroscience, vol. 14, no. 5, pp. 603-611, 2011.

[48] M. Yuzaki, "New insights into the structure and function of glutamate receptors: the orphan receptor delta2 reveals its family's secrets," Keio Journal of Medicine, vol. 52, pp. 9299, 2003.

[49] G. Mandolesi, R. Cesa, E. Autuori, and P. Strata, "An orphan ionotropic glutamate receptor: the $\delta 2$ subunit," Neuroscience, vol. 158, pp. 67-77, 2009.

[50] M. Yuzaki and A. R. Aricescu, "A GluD coming-of-age story," Trends in Neuroscience, vol. 40, no. 3, pp. 138-150, 2017.

[51] K. Hashimoto, T. Yoshida, K. Sakimura, M. Mishina, M. Watanabe, and M. Kano, "Influence of parallel fiberPurkinje cell synapse formation on postnatal development of climbing fiber-Purkinje cell synapses in the cerebellum," Neuroscience, vol. 162, pp. 601-611, 2009.

[52] M. Kano, K. Hashimoto, C. Chen et al., "Impaired synapse elimination during cerebellar development in PKC $\gamma$ mutant mice," Cell, vol. 83, no. 7, pp. 1223-1231, 1995.

[53] M. Kano, K. Hashimoto, H. Kurihara et al., "Persistent multiple climbing fiber innervation of cerebellar Purkinje cells in mice lacking mGluR1," Neuron, vol. 18, no. 1, pp. 71-79, 1997.

[54] M. Kano, K. Hashimoto, M. Watanabe et al., "Phospholipase $c \beta 4$ is specifically involved in climbing fiber synapse elimination in the developing cerebellum," Proceedings of the National Academy of Sciences of the United States of America, vol. 95, no. 26, pp. 15724-15729, 1998.

[55] M. Kano, K. Hashimoto, and T. Tabata, "Type-1 metabotropic glutamate receptor in cerebellar Purkinje cells: a key molecule responsible for long-term depression, endocannabinoid signaling and synapse elimination," Philosophical Transactions of the Royal Society of London B, vol. 363, no. 1500, pp. 2173-2186, 2008.

[56] S. Offermanns, K. Hashimoto, M. Watanabe et al., "Impaired motor coordination and persistent multiple climbing fiber innervation of cerebellar Purkinje cells in mice lacking $\mathrm{G} \alpha \mathrm{q}$," Proceedings of the National Academy of Sciences of the United States of America, vol. 94, no. 25, pp. 1408914094, 1997.

[57] R. Ichikawa, K. Hashimoto, T. Miyazaki et al., "Territories of heterologous inputs onto Purkinje cell dendrites are segregated by mGluR1-dependent parallel fiber synapse elimination," Proceedings of the National Academy of Sciences of the United States of America, vol. 113, no. 8, pp. 2282-2287, 2016.

[58] S. Rabacchi, Y. Bailly, N. Delhaye-Bouchaud, and J. Mariani, "Involvement of the N-methyl d-aspartate (NMDA) receptor in synapse elimination during cerebellar development," Science, vol. 256, no. 5065, pp. 1823-1825, 1992.

[59] S. Kakizawa, M. Yamasaki, M. Watanabe, and M. Kano, "Critical period for activity-dependent synapse elimination in developing cerebellum," Journal of Neuroscience, vol. 20, no. 13, pp. 4954-4961, 2000.

[60] H. Nakayama, T. Miyazaki, K. Kitamura et al., "GABAergic inhibition regulates developmental synapse elimination in the cerebellum," Neuron, vol. 74, no. 2, pp. 384-396, 2012.

[61] L. W. Bosman, J. Hartmann, J. J. Barski et al., "Requirement of $\operatorname{TrkB}$ for synapse elimination in developing cerebellar Purkinje cells," Brain Cell Biology, vol. 35, pp. 87-101, 2006.

[62] E. M. Johnson, E. T. Craig, and H. H. Yeh, “TrkB is necessary for pruning at the climbing fibre-Purkinje cell synapse in the developing murine cerebellum," Journal of Physiology, vol. 582, Part 2, pp. 629-646, 2007.

[63] R. M. Sherrard and A. J. Bower, "Climbing fiber development: do neurotrophins have a part to play?" Cerebellum, vol. 1, no. 4, pp. 265-275, 2002.

[64] R. M. Sherrard, K. J. Dixon, J. Bakouche, J. Rodger, Y. Lemaigre-Dubreuil, and J. Mariani, "Differential expression of TrkB isoforms switches climbing fiber-Purkinje cell synaptogenesis to selective synapse elimination," Developmental Neurobiology, vol. 69, no. 10, pp. 647-662, 2009.

[65] B. Rico, B. Xu, and L. F. Reichardt, "TrkB receptor signaling is required for establishment of GABAergic synapses in the cerebellum," Nature Neuroscience, vol. 5, no. 3, pp. 225233, 2002.

[66] N. Uesaka, M. Uchigashima, T. Mikuni et al., "Retrograde semaphorin signaling regulates synapse elimination in the developing mouse brain," Science, vol. 344, pp. 10201023, 2014.

[67] N. Uesaka, M. Uchigashima, T. Mikuni, H. Hirai, M. Watanabe, and M. Kano, "Retrograde signaling for climbing fiber synapse elimination," Cerebellum, vol. 14, no. 1, pp. 4-7, 2015.

[68] H. M. Zhao, R. J. Wenthold, Y. X. Wang, and R. S. Petralia, "Delta-glutamate receptors are differentially distributed at parallel and climbing fiber synapses on Purkinje cells," Journal of Neurochemistry, vol. 68, pp. 1041-1052, 1997.

[69] R. Yuste and T. Bonhoeffer, "Morphological changes in dendritic spines associated with long-term synaptic plasticity," Annual Review of Neuroscience, vol. 24, pp. 1071-1089, 2001.

[70] D. A. Fortin, T. Srivastava, and T. R. Soderling, "Structural modulation of dendritic spines during synaptic plasticity," The Neuroscientist, vol. 18, no. 4, pp. 326-341, 2012.

[71] C. H. Bailey, E. R. Kandel, and K. M. Harris, "Structural components of synaptic plasticity and memory consolidation," Cold Spring Harbor Perspectives in Biology, vol. 7, no. 7 , article a021758, 2015. 
[72] K.-O. Lai and N. Y. Ip, "Structural plasticity of dendritic spines: the underlying mechanisms and its dysregulation in brain disorders," Biochimica et Biophysica Acta-Molecular Basis of Disease, vol. 1832, no. 12, pp. 2257-2263, 2013.

[73] W. Wefelmeyer, C. Puhl, and J. Burrone, "Homeostatic plasticity of subcellular neuronal structures: from inputs to outputs," Trends in Neuroscience, vol. 39, no. 10, pp. 656667, 2016.

[74] J. Lu and Y. Zuo, "Clustered structural and functional plasticity of dendritic spines," Brain Research Bulletin, vol. 129, pp. 18-22, 2017.

[75] J. Holtmaat, J. T. Trachtenberg, L. Wilbrecht et al., "Transient and persistent dendritic spines in the neocortex in vivo," Neuron, vol. 45, pp. 279-291, 2005.

[76] Y. Zuo, A. Lin, P. Chang, and W. B. Gan, "Development of long-term dendritic spine stability in diverse regions of cerebral cortex," Neuron, vol. 46, pp. 181-189, 2005.

[77] C. C. Chen, J. Lu, and Y. Zuo, "Spatiotemporal dynamics of dendritic spines in the living brain," Frontiers in Neuroanatomy, vol. 8, p. 28, 2014.

[78] M. Fu and Y. Zuo, "Experience-dependent structural plasticity in the cortex," Trends in Neuroscience, vol. 34, pp. 177187, 2011.

[79] P. Caroni, F. Donato, and D. Muller, "Structural plasticity upon learning: regulation and functions," Nature Reviews Neuroscience, vol. 13, pp. 478-490, 2012.

[80] V. A. Alvarez and B. L. Sabatini, "Anatomical and physiological plasticity of dendritic spines," Annual Review of Neuroscience, vol. 30, pp. 79-97, 2007.

[81] A. Holtmaat and K. Svoboda, "Experience-dependent structural synaptic plasticity in the mammalian brain," Nature Reviews Neuroscience, vol. 10, pp. 647-658, 2009.

[82] A. D. Levy, M. H. Omar, and A. Koleske, "Extracellular matrix control of dendritic spine and synapse structure and plasticity in adulthood," Frontiers in Neuroanatomy, vol. 8, p. 116, 2014.

[83] A. Attardo, J. E. Fitzgerald, and M. J. Schnitzer, "Impermanence of dendritic spines in live adult CA1 hippocampus," Nature, vol. 523, pp. 592-596, 2015.

[84] M. Fu, X. Yu, J. Lu, and Y. Zuo, "Repetitive motor learning induces coordinated formation of clustered dendritic spines in vivo," Nature, vol. 483, pp. 92-95, 2012.

[85] A. Hayashi-Takagi, S. Yagishita, M. Nakamura et al., "Labelling and optical erasure of synaptic memory traces in the motor cortex," Nature, vol. 525, pp. 333-338, 2015.

[86] Y. Hatanaka, K. Wada, and T. Kabuta, "Abnormal instability excess density, and aberrant morphology of dendritic spines in prenatally testosterone-exposed mice," Neurochemistry International, vol. 85-86, pp. 53-58, 2015.

[87] M. Phillips and L. Pozzo-Miller, "Dendritic spine dysgenesis in autism related disorders," Neuroscience Letters, vol. 601, pp. 30-40, 2015.

[88] H. Qiao, M. X. Li, C. Xu, H. Chen, S. An, and X. Ma, "Dendritic spines in depression: what we learned from animal models," Neural Plasticity, vol. 2016, Article ID 8056370, 26 pages, 2016.

[89] Y. Bernardinelli, I. Nikonenko, and D. Muller, "Structural plasticity: mechanisms and contribution to developmental psychiatric disorders," Frontiers in Neuroanatomy, vol. 8, p. 123, 2014.
[90] R. Canitano, "New experimental treatments for core social domain in autism spectrum disorders," Frontiers in Pediatrics, vol. 2, p. 61, 2014.

[91] C. Sotelo, "Purkinje cell ontogeny: formation and maintenance of spines," Progress in Brain Research, vol. 48, pp. 149-170, 1978.

[92] R. Cesa and P. Strata, "Axonal competition in the synaptic wiring of the cerebellar cortex during development and in the mature cerebellum," Neuroscience, vol. 162, pp. 624632, 2009.

[93] F. Benedetti, P. G. Montarolo, P. Strata, and L. Tosi, "Functional synaptogenesis in the cerebellar cortex after inferior olive lesion," in Nervous System Regeneration, B. Haber, J. R. Perez-Polo, G. Hashim and A. M. L. Giuffrida Stella, Eds., pp. 461-464, Alan Liss, New York, NY, USA, 1983.

[94] F. Benedetti and P. Strata, "Functional synaptogenesis in the cerebellar cortex after inferior olive lesion," in Biological Aspects of Neuron Activity, V. Bonavita and F. Piccoli, Eds., pp. 97-107, Fidia Biomedical Information, Padova, Italy, 1989.

[95] D. Sotelo, E. Hillman, A. J. Zamora, and R. Llinás, “Climbing fiber deafferentation: its action on Purkinje cell dendritic spines," Brain Research, vol. 98, pp. 574-581, 1975.

[96] F. Rossi, L. Wiklund, J. J. van der Want, and P. Strata, "Reinnervation of cerebellar Purkinje cells by climbing fibres surviving a subtotal lesion of the inferior olive in the adult rat: I. Development of new collateral branches and terminal plexuses," Journal of Comparative Neurology, vol. 308, pp. 513-535, 1991.

[97] R. Cesa, L. Morando, and P. Strata, "Glutamate receptor delta2 subunit in activity-dependent heterologous synaptic competition," Journal of Neuroscience, vol. 23, pp. 23632370, 2003.

[98] R. Cesa, L. Morando, and P. Strata, "Purkinje cell spinogenesis during architectural rewiring in the mature cerebellum," European Journal of Neuroscience, vol. 22, pp. 579-586, 2005.

[99] F. Rossi, T. Borsello, E. Vaudano, and P. Strata, "Regressive modifications of climbing fibres following Purkinje cell degeneration in the cerebellar cortex of the adult rat," Neuroscience, vol. 53, pp. 759-778, 1993.

[100] F. Rossi, A. Jankovski, and C. Sotelo, "Target neuron controls the integrity of afferent axon phenotype: a study on the Purkinje cell-climbing fiber system in cerebellar mutant mice," Journal of Neuroscience, vol. 15, pp. 2040-2056, 1995.

[101] J. A. Armengol, C. Sotelo, P. Angaut, and R. M. AlvaradoMallart, "Organization of host afferents to cerebellar grafts implanted into kainate lesioned cerebellum in adult rats," European Journal of Neuroscience, vol. 1, pp. 75-93, 1989.

[102] C. Sotelo and R. M. Alvarado-Mallart, "Reconstruction of the defective cerebellar circuitry in adult Purkinje cell degeneration mutant mice by Purkinje cell replacement through transplantation of solid embryonic implants," Neuroscience, vol. 20, pp. 1-22, 1987.

[103] T. Rossi, T. Borsello, and P. Strata, "Embryonic Purkinje cells grafted on the surface of the cerebellar cortex integrate in the adult unlesioned cerebellum," European Journal of Neuroscience, vol. 4, pp. 589-593, 1992.

[104] F. Tempia, M. Bravin, and P. Strata, "Postsynaptic currents and short-term synaptic plasticity in Purkinje cells grafted onto an uninjured adult cerebellar cortex," European Journal of Neuroscience, vol. 8, pp. 2690-2701, 1996. 
[105] L. Morando, R. Cesa, R. Rasetti, R. Harvey, and P. Strata, "Role of glutamate $\delta$-2 receptors in activity-dependent competition between heterologous afferent fibers," Proceedings of the National Academy of Sciences of the United States of America, vol. 98, pp. 9954-9959, 2001.

[106] R. Cesa and P. Strata, "Activity-dependent axonal and synaptic plasticity in the cerebellum," Psychoneuroendocrinology, vol. 32, pp. S31-S35, 2007.

[107] R. Cesa, L. Morando, and P. Strata, "Transmitter-receptor mismatch in GABAergic synapses in the absence of activity," Proceedings of the National Academy of Sciences of the United States of America, vol. 105, pp. 18988-18993, 2008.

[108] R. Cesa, F. Premoselli, A. Renna, I. M. Ethell, E. B. Pasquale, and P. Strata, "Eph receptors are involved in the activitydependent synaptic wiring in the mouse cerebellar cortex," PLoS One, vol. 6, no. 4, article e19160, 2011.

[109] R. Klein, "Bidirectional modulation of synaptic functions by Eph/ephrin signaling," Nature Neuroscience, vol. 12, pp. 1520, 2009.

[110] Y. Yamaguchi and E. B. Pasquale, "Eph receptors in the adult brain," Current Opinion in Neurobiolology, vol. 14, pp. 288296, 2004.

[111] J. Aoto and L. Chen, "Bidirectional ephrin/Eph signaling in synaptic functions," Brain Research, vol. 1184, pp. 72-80, 2007.

[112] J. Lippman and A. Dunaevsky, "Dendritic spine morphogenesis and plasticity," Journal of Neurobiology, vol. 64, pp. 4757, 2005.

[113] F. Jaudon, R. Raynaud, J. Wehrlé et al., “The RhoGEF DOCK10 is essential for dendritic spine morphogenesis," Molecular Biology of the Cell, vol. 26, no. 11, pp. 2112-2127, 2015.

[114] C. Nava, B. Keren, C. Mignot et al., "Prospective diagnostic analysis of copy number variants using SNP microarrays in individuals with autism spectrum disorders," European Journal of Human Genetics, vol. 22, pp. 71-78, 2013.

[115] T. G. Heintz, R. Eva, and J. W. Fawcett, "Regional regulation of Purkinje cell dendritic spines by integrins and Eph/ Ephrins," PLoS One, vol. 11, no. 8, article e0158558, 2016.

[116] C. Orlando, J. Ster, U. Gerber, J. W. Fawcett, and O. Raineteau, "Peridendritic chondroitin sulfate proteoglycans restrict structural plasticity in an integrin-dependent manner," Journal of Neuroscience, vol. 32, pp. 18009-18017, 2012.

[117] O. Senkov, P. Andjus, L. Radenovic, E. Soriano, and A. Dityatev, "Neural ECM molecules in synaptic plasticity, learning, and memory," Progress in Brain Research, vol. 214, pp. 53-80, 2014.

[118] N. Vitureira, M. Letellier, and Y. Goda, "Homeostatic synaptic plasticity: from single synapses to neural circuits," Current Opinion in Neurobiology, vol. 22, no. 3, pp. 516-521, 2012.

[119] B. McGeachie, L. A. Cingolani, and Y. Goda, "Stabilising influence: integrins in regulation of synaptic plasticity," Neuroscience Research, vol. 70, no. 1, pp. 24-29, 2011.

[120] P. M. Whitaker-Azmitia, "Serotonin and brain development: role in human developmental diseases," Brain Research Bulletin, vol. 56, no. 5, pp. 479-485, 2001.

[121] P. Gaspar, O. Cases, and L. Maroteaux, "The developmental role of serotonin: news from mouse molecular genetics," Nature Review Neuroscience, vol. 4, pp. 1002-1012, 2003.

[122] A. Daubert and B. G. Condron, "Serotonin: a regulator of neuronal morphology and circuitry," Trends in Neurosciences, vol. 33, no. 9, pp. 424-434, 2010.
[123] S. Migliarini, G. Pacini, B. Pelosi, G. Lunardi, and M. Pasqualetti, "Lack of brain serotonin affects postnatal development and serotonergic neuronal circuitry formation," Molecular Psychiatry, vol. 18, no. 10, pp. 1106-1118, 2013.

[124] J. M. Lauder, "Ontogeny of the serotonergic system in the rat: serotonin as a developmental signal," Annals of the New York Academy of Sciences, vol. 600, pp. 297-313, 1990.

[125] C. Chugani, O. Muzik, M. Behen et al., "Developmental changes in brain serotonin synthesis capacity in autistic and nonautistic children," Annals of Neurology, vol. 45, pp. 287295, 1999.

[126] A. Abi-Dargham, "Alterations of serotonin transmission in schizophrenia," International Review of Neurobiology, vol. 78, pp. 133-164, 2007.

[127] M. Oostland and J. A. van Hooft, "The role of serotonin in cerebellar development,” Neuroscience, vol. 248, pp. 201212, 2013.

[128] D. Hoyer, D. E. Clarke, J. R. Fozard et al., "International union of pharmacology classification of receptors for 5hydroxytryptamine (serotonin)," Pharmacological Reviews, vol. 46, pp. 157-120, 1994.

[129] L. Speranza, A. Chambery, M. Di Domenico et al., "The serotonin receptor 7 promotes neurite outgrowth via ERK and Cdk5 signaling pathways," Neuropharmacology, vol. 67, pp. 155-167, 2013.

[130] D. Hoyer, J. P. Hannon, and G. R. Martin, "Molecular, pharmacological and functional diversity of 5-HT receptors," Pharmacology Biochemistry and Behavior, vol. 71, pp. 533554, 2002.

[131] G. Lidov and M. E. Molliver, "An immunohistochemical study of serotonin neuron development in the rat: ascending pathways and terminal fields," Brain Research Bulletin, vol. 4, pp. 389-430, 1982.

[132] G. A. Bishop, R. H. Ho, and J. S. King, “A temporal analysis of the origin and distribution of serotoninergic afferents in the cerebellum of pouch young opossums," Anatomy and Embryology, vol. 179, pp. 33-48, 1988.

[133] G. A. Bishop and R. H. Ho, "The distribution and origin of serotonin immunoreactivity in the rat cerebellum," Brain Research, vol. 331, pp. 195-207, 1985.

[134] M. Oostland, M. R. Buijink, G. M. Teunisse, L. von Oerthel, M. P. Smidt, and J. A. van Hooft, "Distinct temporal expression of 5-HT(1A) and 5-HT(2A) receptors on cerebellar granule cells in mice," Cerebellum, vol. 4, pp. 491-500, 2014.

[135] T. Maeshima, T. Shiga, R. Ito, and N. Okado, "Expression of serotonin2A receptors in Purkinje cells of the developing rat cerebellum," Neuroscience Research, vol. 50, pp. 411417, 2004

[136] M. Kondoh, T. Shiga, and N. Okado, "Regulation of dendrite formation of Purkinje cells by serotonin through serotonin $1 \mathrm{~A}$ and serotonin $2 \mathrm{~A}$ receptors in culture," Neuroscience Research, vol. 48, pp. 101-109, 2004.

[137] E. F. Trakhtenberg and J. L. Goldberg, "The role of serotonin in axon and dendrite growth," International Review of Neurobiology, vol. 106, pp. 105-126, 2012.

[138] M. Oostland, J. Sellmeijer, and J. A. van Hoof, “Transient expression of functional serotonin 5-HT3 receptors by glutamatergic granule cells in the early postnatal mouse cerebellum," Journal of Physiology, vol. 589, pp. 4837-4846, 2011.

[139] M. Oostland, M. R. Buijink, and J. A. van Hooft, "Serotonergic control of Purkinje cell maturation and climbing fiber 
elimination by 5 -HT3 receptors in the juvenile mouse cerebellum," Journal of Physiology, vol. 591, pp. 1793-1807, 2013.

[140] J. Altman and S. A. Bayer, Development of the Cerebellar System in Relation to Its Evolution, Structure, and Functions, CRC Press, Boca Raton, FL, USA, 1996.

[141] A. Pazos and J. M. Palacios, "Quantitative autoradiographic mapping of serotonin receptors in the rat brain. I. Serotonin-1 receptors," Brain Research, vol. 346, pp. 205230, 1985.

[142] F. J. Geurts, E. De Schutter, and J. P. Timmermans, "Localization of 5-HT2A, 5-HT3, 5-HT5A and 5-HT7 receptor-like immunoreactivity in the rat cerebellum," Journal of Chemical Neuroanatomy, vol. 24, pp. 65-74, 2002.

[143] X. Li, W. Zhu, M. S. Roh, A. B. Friedman, K. Rosborough, and R. S. Jope, "In vivo regulation of glycogen synthase kinase3beta (GSK3beta) by serotonergic activity in mouse brain," Neuropsychopharmacology, vol. 29, pp. 1426-1431, 2004.

[144] P. Lippiello, E. Hoxha, L. Speranza et al., "The 5-HT7 receptor triggers cerebellar long-term synaptic depression via PKC-MAPK," Neuropharmacology, vol. 101, pp. 426438, 2016.

[145] V. Chan-Palay, "Fine structure of labelled axons in the cerebellar cortex and nuclei of rodents and primates after intraventricular infusions with tritiated serotonin," Anatomy and Embryology, vol. 148, pp. 235-265, 1975.

[146] A. Beaudet and C. Sotelo, "Synaptic remodeling of serotonin axon terminals in rat agranular cerebellum," Brain Research, vol. 206, pp. 305-329, 1981.

[147] H. Mitoma and S. Konishi, "Monoaminergic long-term facilitation of GABA- mediated inhibitory transmission at cerebellar synapses," Neuroscience, vol. 88, pp. 871-883, 1999.

[148] S. Dieudonné, "Serotonergic neuromodulation in the cerebellar cortex: cellular, synaptic, and molecular basis," The Neuroscientist, vol. 7, pp. 207-219, 2001.

[149] G. Maura, A. Ricchetti, and M. Raiteri, "Serotonin inhibits the depolarization-evoked release of endogenous glutamate from rat cerebellar nerve endings," Neuroscience Letters, vol. 67, pp. 218-222, 1986.

[150] E. Hoxha, F. Tempia, P. Lippiello, and M. C. Miniaci, "Modulation, plasticity and pathophysiology of the parallel fiber-Purkinje cell synapse," Frontiers in Synaptic Neuroscience, vol. 8, p. 35, 2016.

[151] Y. Miyashita and E. Watanabe, "Loss of vision-guided adaptation of the vestibulo-ocular reflex after depletion of brain serotonin in the rabbit," Neuroscience Letters, vol. 51, pp. 177-182, 1984.

[152] M. C. Lai, M. V. Lombardo, and S. Baron-Cohen, "Autism," Lancet, vol. 383, no. 9920, pp. 896-910, 2014.

[153] D. R. Hampson and G. J. Blatt, "Autism spectrum disorders and neuropathology of the cerebellum," Frontiers in Neuroscience, vol. 9, p. 420, 2015.

[154] E. Courchesne, E. Redcay, J. T. Morgan, and D. P. Kennedy, "Autism at the beginning: microstructural and growth abnormalities underlying the cognitive and behavioral phenotype of autism," Development and Psychopathology, vol. 17, no. 3, pp. 577-597, 2005.

[155] G. Allen, "The cerebellum in autism," Clinical Neuropsychiatry, vol. 2, pp. 321-337, 2005.

[156] P. T. Tsai, C. Hull, Y. Chu et al., "Autistic-like behaviour and cerebellar dysfunction in Purkinje cell Tsc1 mutant mice," Nature, vol. 488, no. 7413, pp. 647-651, 2012.
[157] D. Cupolillo, E. Hoxha, A. Faralli et al., "Autistic-like traits and cerebellar dysfunction in Purkinje cell PTEN knock-out mice," Neuropsychopharmacology, vol. 41, no. 6, pp. 14571466, 2016.

[158] S. Peter, M. M. Ten Brinke, J. Stedehouder et al., "Dysfunctional cerebellar Purkinje cells contribute to autism-like behaviour in Shank2-deficient mice," Nature Communications, vol. 7, article 12627, 2016.

[159] E. Fujita-Jimbo and T. Momoi, "Specific expression of FOXP2 in cerebellum improves ultrasonic vocalization in heterozygous but not in homozygous Foxp2 (R552H) knock-in pups," Neuroscience Letters, vol. 566, pp. 162-166, 2014.

[160] J. Hutsler and H. Zhang, "Increased dendritic spine densities on cortical projection neurons in autism spectrum disorders," Brain Research, vol. 1309, pp. 83-94, 2010.

[161] V. Martínez-Cerdeño, "Dendrite and spine modifications in autism and related neurodevelopmental disorders in patients and animal models," Developmental Neurobiology, vol. 77, no. 4, pp. 393-404, 2017.

[162] L. McBride, E. A. Varga, M. T. Pastore et al., "Confirmation study of PTEN mutations among individuals with autism or developmental delays/mental retardation and macrocephaly," Autism Research, vol. 3, no. 3, pp. 137-141, 2010.

[163] N. Chalhoub and S. J. Baker, "PTEN and the PI3-kinase pathway in cancer," Annual Review of Pathology, vol. 4, pp. 127-150, 2009.

[164] R. Endersby and S. J. Baker, "PTEN signaling in brain: neuropathology and tumorigenesis," Oncogene, vol. 27, no. 41, pp. 5416-5430, 2008.

[165] S. Ha, D. Lee, Y. S. Cho et al., "Cerebellar Shank2 regulates excitatory synapse density, motor coordination, and specific repetitive and anxiety-like behaviors," Journal of Neuroscience, vol. 36, no. 48, pp. 12129-12143, 2016.

[166] S. Leblond, J. Heinrich, R. Delorme et al., "Genetic and functional analyses of SHANK2 mutations suggest a multiple hit model of autism spectrum disorders," PLoS Genetics, vol. 8, article e1002521, 2012.

[167] M. J. Schmeisser, E. Ey, S. Wegener et al., "Autistic-like behaviours and hyperactivity in mice lacking ProSAP1/ Shank2," Nature, vol. 486, pp. 256-260, 2012.

[168] H. Won, H. R. Lee, H. Y. Gee et al., "Autistic-like social behaviour in Shank2-mutant mice improved by restoring NMDA receptor function," Nature, vol. 486, pp. 261-265, 2012.

[169] W. Jones and A. Klin, "Attention to eyes is present but in decline in 2-6-month-old infants later diagnosed with autism," Nature, vol. 504, pp. 427-431, 2013.

[170] H. Geschwind and M. W. State, "Gene hunting in autism spectrum disorder: on the path to precision medicine," Lancet Neurology, vol. 14, no. 11, pp. 1109-1120, 2015.

[171] S. W. Hulbert and Y. H. Jiang, "Cellular and circuitry bases of autism: lessons learned from the temporospatial manipulation of autism genes in the brain," Neuroscience Bulletin, vol. 33, no. 2, pp. 205-218, 2017.

[172] M. McGraw, R. C. Samaco, and H. Y. Zoghbi, “Adult neural function requires MeCP2," Science, vol. 333, no. 6039, p. $186,2011$.

[173] M. Lang, R. G. Wither, S. Colic et al., "Rescue of behavioral and EEG deficits in male and female Mecp2-deficient mice by delayed Mecp2 gene reactivation," Human Molecular Genetics, vol. 23, pp. 303-318, 2014. 
[174] S. Silva-Santos, G. M. van Woerden, C. F. Bruinsma et al., "Ube3a reinstatement identifies distinct developmental windows in a murine Angelman syndrome model," Journal of Clinical Investigation, vol. 125, pp. 2069-2076, 2015.

[175] G. Rabaneda, E. Robles-Lanuza, J. L. Nieto-Gonzalez, and F. G. Scholl, "Neurexin dysfunction in adult neurons results in autistic-like behavior in mice," Cell Reports, vol. 8, pp. 338-346, 2014.

[176] Y. Mei, P. Monteiro, Y. Zhou et al., "Adult restoration of Shank3 expression rescues selective autistic-like phenotypes," Nature, vol. 530, pp. 481-484, 2016.

[177] Y. Fujita, A. Tanabe, M. Shiota et al., "Ultrasonic vocalization impairment of Foxp2 (R552H) knockin mice related to speech-language disorder and abnormality of Purkinje cells," Proceedings of the National Academy of Sciences of the United States of America, vol. 105, no. 8, pp. 3117-3122, 2008.

[178] W. Shu, J. Y. Cho, Y. Jiang et al., "Altered ultrasonic vocalization in mice with a disruption in the Foxp2 gene," Proceedings of the National Academy of Sciences of the United States of America, vol. 102, no. 27, pp. 9643-9648, 2005.

[179] C. L. Muller, A. M. Anacker, and J. Veenstra-Vanderweele, "The serotonin system in autism spectrum disorder: from biomarker to animal models," Neuroscience, vol. 321, pp. 24-41, 2016.

[180] L. H. Hough and S. Segal, "Effects of developmental hyperserotonemia on the morphology of rat dentate nuclear neurons," Neuroscience, vol. 322, pp. 178-194, 2016.

[181] F. Gu, V. Chauhan, and A. Chauhan, "Monoamine oxidase-A and $\mathrm{B}$ activities in the cerebellum and frontal cortex of children and young adults with autism," Journal of Neuroscience Research, 2017.

[182] O. Cases, C. Lebrand, B. Giros et al., "Plasma membrane transporters of serotonin, dopamine, and norepinephrine mediate serotonin accumulation in atypical locations in the developing brain of monoamine oxidase A knock-outs," The Journal of Neuroscience, vol. 18, no. 17, pp. 6914-6927, 1998.

[183] C. Singh, M. Bortolato, N. Bali et al., "Cognitive abnormalities and hippocampal alterations in monoamine oxidase A and B knockout mice," Proceedings of the National Academy of Sciences of the United States of America, vol. 110, pp. 12816-12821, 2013. 

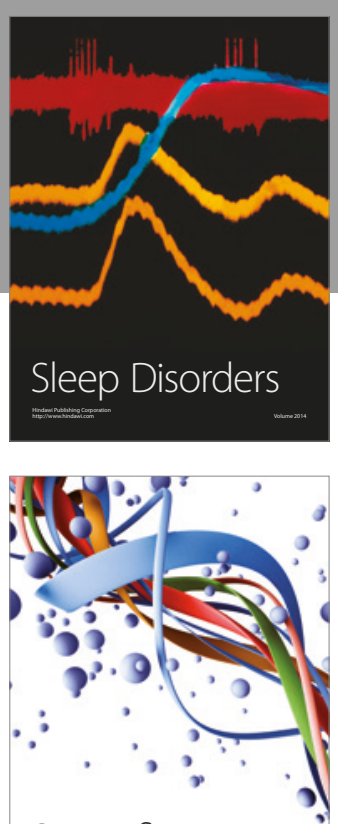

Scientifica
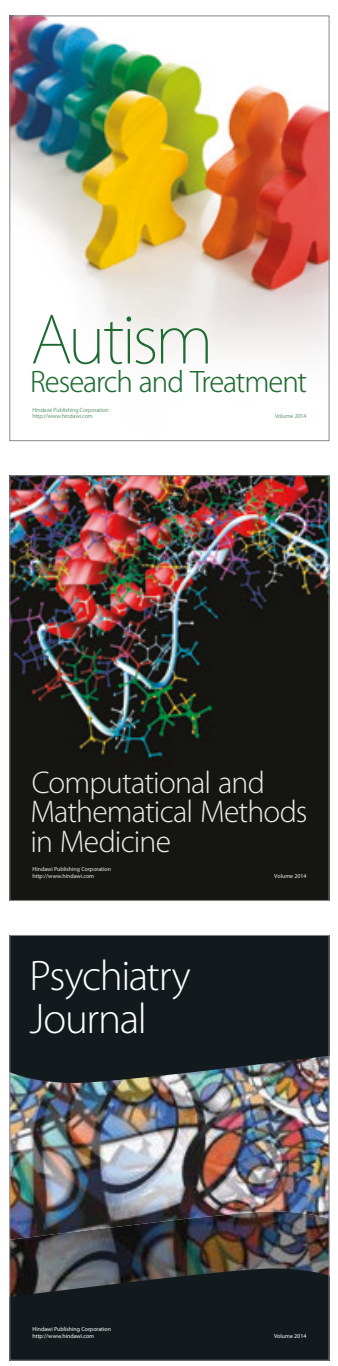
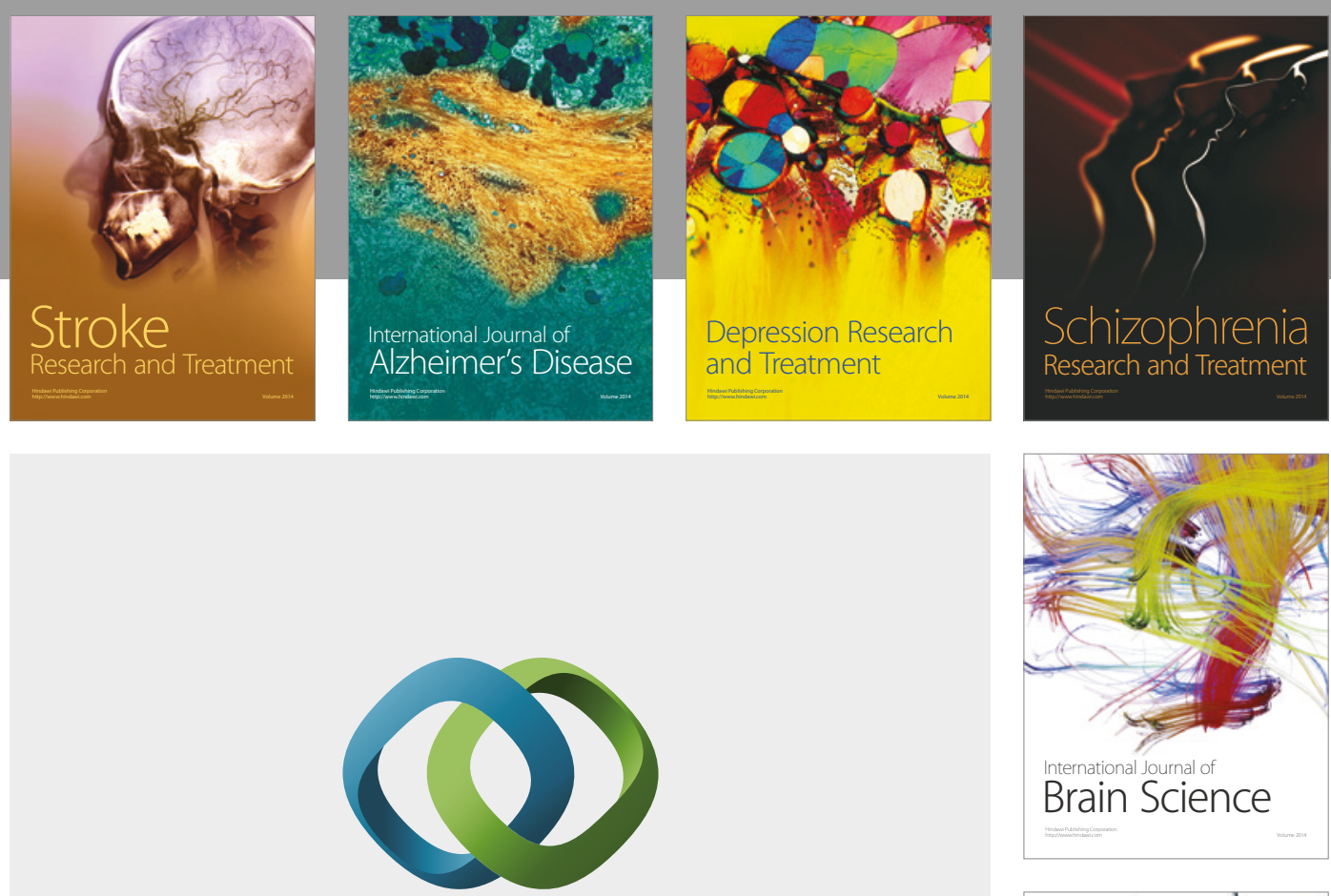

\section{Hindawi}

Submit your manuscripts at

https://www.hindawi.com
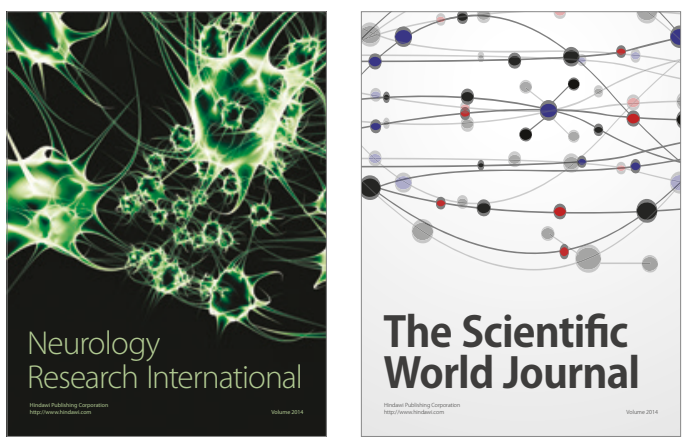

The Scientific World Journal

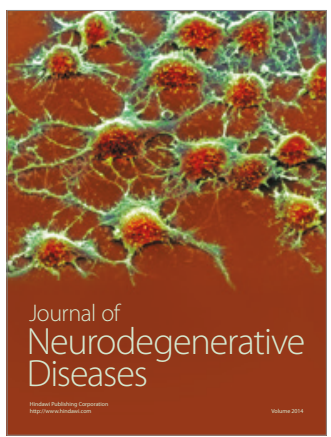

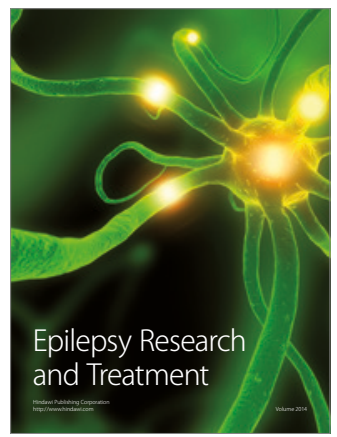

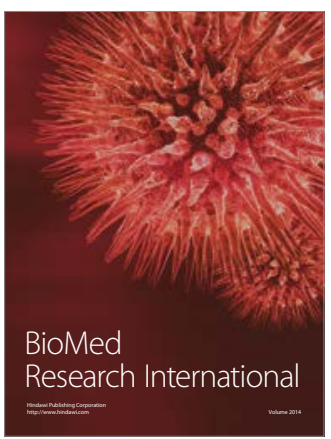

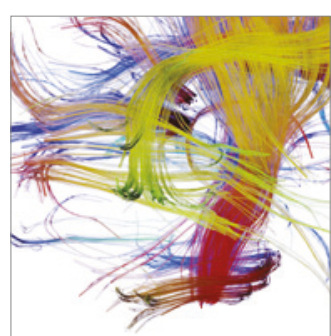

Brain Science

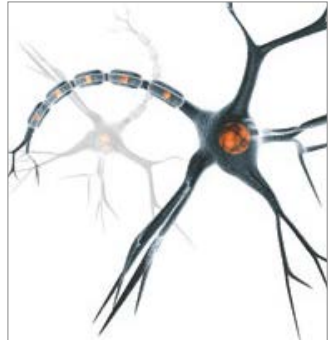

Neural Plasticity
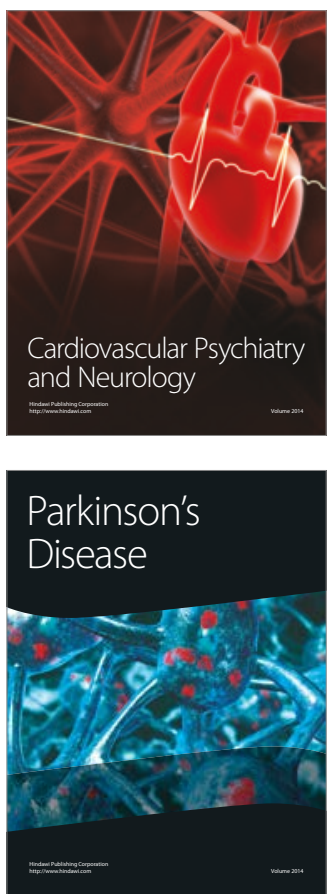